\title{
Rastreabilidade de subprodutos de origem animal em dietas com levedura e trigo para frangos
}

\author{
Rosana Gottmann(1), Antonio Celso Pezzato(1), Carlos Ducatti(2), Juliana Célia Denadai ${ }^{(1)}$, Cleusa Móri(2), \\ Mariela Akie Okino Mituo ${ }^{(1)}$ e José Roberto Sartori ${ }^{(1)}$
}

\begin{abstract}
(1)Universidade Estadual Paulista (Unesp), Faculdade de Medicina Veterinária e Zootecnia, Instituto de Biociências, Centro de Isótopos Estáveis, Distrito de Rubião Júnior, Caixa Postal 510, CEP 18618-000 Botucatu, SP. E-mail: rosanagtt@yahoo.com.br, cpezzato@fca.unesp. br, denadaijc@gmail.com, mariela_okino@yahoo.com.br, jrsatori@fca.unesp.br (2)Unesp, Instituto de Biociências, Centro de Isótopos Estáveis. E-mail: ducatti@ibb.unesp.br, cleusamori@uol.com.br
\end{abstract}

Resumo - O objetivo deste trabalho foi rastrear a inclussão de farinhas de origem animal em rações para frango de corte com ou sem levedura de cana-de-açúcar e farelo de trigo, por meio da análise do músculo peitoral das aves pelas técnicas dos isótopos estáveis de carbono e nitrogênio. Foram utilizados 210 pintos machos (Cobb), com um dia de idade, distribuídos aleatoriamente em sete tratamentos de 30 aves cada, tendo sido um tratamento controle (dieta vegetal) e seis com inclusão de farinha de carne e ossos bovina ou farinha de vísceras de aves na dieta, com ou sem levedura de cana-de-açúcar e farelo de trigo. Aos 42 dias de idade, foram abatidas quatro aves, por tratamento, escolhidas ao acaso, cujo músculo peitoral foi retirado para análise da razão isotópica. Os resultados obtidos foram submetidos à análise multivariada. Os tratamentos experimentais diferiram do tratamento controle, e foi identificada a inclusão de farinha de origem animal, pelas técnicas dos isótopos estáveis, mesmo com inclusão de levedura ou farelo de trigo na dieta.

Termos para indexação: Gallus gallus, carbono-13, certificação, farinha de carne e ossos, farinha de vísceras, nitrogênio-15.

\section{Traceability of animal byproducts in diets containing yeast and wheat meal for broilers}

\begin{abstract}
The aim of this paper was to trace the presence of meals from animal origin, in diets for broilers with or without yeast and wheat meal, through the analysis of breast muscle, by using carbon and nitrogen stable isotope techniques. Two hundred ten male chicks (Cobb) one-day old were randomly distributed to seven treatments (30 birds each), with a control diet (exclusively vegetal), and six diets containing meat and bone meal or poultry offal meal, with or without yeast and wheat meal in their compositions. At 42 days of age, four broilers randomly chosen, by treatment were slaughtered, and their breast muscles were collected for isotopic ratio analysis. The isotopic results were analyzed by multivariate statistical analysis of variance. The treatments differed from the control and the inclusion of meals of animal origin was identified by stable isotope techniques, even when there was yeast or wheat meal included in the diet.
\end{abstract}

Index terms: Gallus gallus, carbon-13, certification, meat and bones meal, poultry offal meal, nitrogen-15.

\section{Introdução}

As tendências internacionais do mercado são as de imposição de exigências cada vez mais rigorosas à importação de produtos brasileiros, assim, a rastreabilidade torna-se ferramenta relevante, para assegurar um produto de qualidade aos consumidores. Porém, aplicada isoladamente a rastreabilidade não traz segurança aos produtos nem aos processos, por isso, deve estar associada a outros sistemas de controle de qualidade (Iba et al., 2003). Há, assim, necessidade do desenvolvimento de tecnologias independentes, para a certificação de carnes, de modo a tranqüilizar os consumidores, proteger designações regionais e assegurar uma competição justa (Ilbery et al., 2000).

Problemas ocorridos anteriomente - como a encefalopatia espongiforme bovina (EEB), a preocupação com os organismos geneticamente modificados (OGM), a febre aftosa e a gripe aviária também contribuíram para o desenvolvimento de um sistema que permita fiscalizar toda a cadeia alimentar (Regattieri et al., 2007).

Foram adotadas medidas relacionadas à manutenção da qualidade dos produtos de origem animal, à ausência de resíduos de substâncias químicas nas rações; identificação, registro e rotulagem da carne e de

Pesq. agropec. bras., Brasília, v.43, n.12, p.1641-1647, dez. 2008 
produtos à base de carne bovina (Comunidade Européia, 2000), e restrição da utilização de subprodutos de origem animal em rações de animais da mesma espécie (Comunidade Européia, 2002).

Muitos importadores da carne de frango brasileira, como a União Européia e o Oriente Médio, exigem que as aves não recebam alimentação com ingredientes de origem animal nem promotores de crescimento (Bellaver et al., 2005), o que direciona para a produção de animais alimentados com rações estritamente vegetais.

Muitos métodos têm sido propostos para identificar a presença de subprodutos de origem animal em rações para animais, entre eles a técnica dos isótopos estáveis, que ainda possibilita a determinação dos subprodutos no produto final.

A espectrometria de massas, pela análise da razão isotópica do carbono associado ao nitrogênio, no produto final, foi utilizada por Oliveira (2005) e Carrijo et al. (2006), em pesquisas com frangos de corte, nos quais determinaram a presença de farinha de vísceras de aves e farinha de carne e ossos bovina, respectivamente, na alimentação das aves. Nessa mesma linha de pesquisa, Móri et al. (2007) e Denadai (2008) também identificaram a presença de farinha de origem animal na dieta dos animais, pela análise da carne de codornas e ovos de poedeiras comerciais, respectivamente.

A razão isotópica do carbono $\left({ }^{13} \mathrm{C} /{ }^{12} \mathrm{C}\right)$ tem sido utilizada com sucesso para testar a autenticidade, a qualidade e a origem geográfica de vários produtos como sucos de frutas (Bricout \& Koziet, 1987; Koziet et al., 1993), vinho (Martin et al., 1988), mel (Brookes et al., 1991; White et al., 1998), produtos lácteos (Rossmann et al., 2000; Manca et al., 2001), óleos vegetais (Kelly et al., 1997), e para a caracterização e diferenciação do regime dietético de suínos ibéricos, de acordo com a alimentação recebida no período de engorda (González Martin et al., 1999). A razão isotópica do carbono associada à do nitrogênio $\left({ }^{15} \mathrm{~N} /{ }^{14} \mathrm{~N}\right)$ permitiu a certificação da origem geográfica e de tipos de alimentação de ovinos (Piasentier et al., 2003).

Este trabalho teve como objetivo avaliar se é possível a rastreabilidade da farinha de carne e ossos bovina e da farinha de vísceras de aves, mesmo com inclusão de outros ingredientes, como o farelo de trigo e a levedura de cana-de-açúcar, em dietas para frangos de corte, por meio da análise do músculo peitoral das aves com uso das técnicas dos isótopos estáveis de carbono e nitrogênio.

\section{Material e Métodos}

O experimento foi conduzido na Unesp, Campus de Botucatu, Faculdade de Medicina Veterinária e Zootecnia, Laboratório de Nutrição de Aves, de 13 de setembro a 24 de outubro de 2005 . Foram utilizados 210 pintos de corte machos, da linhagem Cobb, com um dia de idade, vacinados no incubatório contra as doenças de Gumboro, Marek e bouba aviária.

As aves foram alojadas em aviário convencional, distribuídas aleatoriamente em sete tratamentos, com 30 aves cada. Os tratamentos se constituíram de: TC (tratamento controle), dieta vegetal; FC, inclusão de farinha de carne e ossos bovina; FV, inclusão de farinha de vísceras de aves; FCV, inclusão de farinha de carne e ossos bovina e farinha de vísceras de aves; FCLT, inclusão de farinha de carne e ossos bovina, levedura e farelo de trigo; FVLT, inclusão de farinha de vísceras de aves, levedura e farelo de trigo; FCVLT, inclusão de farinha de carne e ossos bovina, farinha de vísceras de aves, levedura e farelo de trigo.

O programa de arraçoamento foi dividido em duas fases: inicial, de 1 a 21 dias e final, de 22 a 42 dias (Tabela 1). As rações foram elaboradas para serem isoprotéicas e isoenergéticas, formuladas à base de milho e farelo de soja, conforme adaptações das recomendações de Rostagno et al. (2005). A inclusão de levedura, farelo de trigo, farinha de vísceras de aves e farinha de carne e ossos bovina foi padronizada, para que as dietas fossem equivalentes em proteína bruta ao tratamento $\mathrm{FC}$, com $6 \%$ de farinha de carne e ossos bovina.

O fornecimento de água e ração foi ad libitum, durante todo $\mathrm{o}$ período experimental. Para $\mathrm{o}$ aquecimento inicial cada box foi equipado com uma campânula, que foi retirada no sétimo dia de idade dos pintos. $\mathrm{O}$ fornecimento de luz às aves foi constante, com 24 horas de luz diárias, e o controle da temperatura e de ventilação ambiental foi feito manualmente, pelo manejo das cortinas laterais do galpão.

Aos 42 dias de idade, para a coleta do músculo peitoral (pectoralis major), foram retiradas aleatoriamente quatro aves por tratamento, sacrificadas por deslocamento cervical, e cada ave abatida foi considerada uma repetição. Essas amostras foram 
Tabela 1. Composição percentual dos ingredientes e composição nutricional, de rações experimentais iniciais (1 a 21 dias) e finais (22 a 42dias) de frangos de corte.

\begin{tabular}{|c|c|c|c|c|c|c|c|}
\hline \multirow[t]{2}{*}{ Ingrediente $(\%)$} & \multicolumn{7}{|c|}{ Tratamentos } \\
\hline & TC & $\mathrm{FC}$ & FV & FCV & FCLT & FVLT & FCVLT \\
\hline & \multicolumn{7}{|c|}{ Rações experimentais iniciais } \\
\hline Milho & 62,40 & 63,04 & 62,25 & 62,63 & 57,21 & 56,55 & 60,10 \\
\hline Farelo de soja & 33,66 & 28,01 & 28,28 & 28,14 & 29,19 & 29,40 & 28,65 \\
\hline Óleo de soja & 0,20 & - & - & - & 1,13 & 0,98 & 0,45 \\
\hline $\mathrm{FCOB}^{(2)}$ & - & 6,00 & - & 3,00 & 2,00 & - & 1,50 \\
\hline $\mathrm{FVA}^{(3)}$ & - & - & 4,30 & 2,20 & - & 1,40 & 1,10 \\
\hline Farelo de trigo & - & - & - & - & 5,30 & 5,30 & 3,90 \\
\hline Levedura de cana & - & - & - & - & 2,30 & 2,30 & 1,70 \\
\hline Calcário calcítico & 1,00 & 0,80 & 0,97 & 0,92 & 0,99 & 1,03 & 0,99 \\
\hline Fosfato bicálcico & 1,78 & - & 1,22 & 0,43 & 1,01 & 1,53 & 1,05 \\
\hline DL-Metionina & 0,23 & 0,25 & 0,20 & 0,23 & 0,23 & 0,22 & 0,23 \\
\hline L-Lisina & 0,18 & 0,23 & 0,18 & 0,21 & 0,17 & 0,16 & 0,18 \\
\hline Caulim & - & 1,10 & 2,00 & 1,7 & - & - & \\
\hline Sal comum & 0,37 & 0,37 & 0,37 & 0,37 & 0,37 & 0,37 & 0,37 \\
\hline Cloreto de colina $70 \%$ & 0,05 & 0,05 & 0,05 & 0,05 & 0,05 & 0,05 & 0,05 \\
\hline Supl. vitamínico ${ }^{(4)}$ & 0,10 & 0,10 & 0,10 & 0,10 & 0,10 & 0,10 & 0,10 \\
\hline Supl. mineral ${ }^{(5)}$ & 0,05 & 0,05 & 0,05 & 0,05 & 0,05 & 0,05 & 0,05 \\
\hline Total & 100,00 & 100,00 & 100,00 & 100,00 & 100,00 & 100,00 & 100,00 \\
\hline \multicolumn{8}{|c|}{ Composição nutricional calculada } \\
\hline EM $\left(\mathrm{kcal} \mathrm{kg}^{-1}\right)$ & 2.900 & 2.900 & 2.900 & 2.900 & 2.900 & 2.900 & 2.900 \\
\hline PB $(\%)$ & 20,70 & 20,70 & 20,70 & 20,70 & 20,70 & 20,70 & 20,70 \\
\hline Cálcio (\%) & 0,93 & 1,00 & 0,93 & 0,93 & 0,93 & 0,93 & 0,93 \\
\hline P disponível (\%) & 0,44 & 0,51 & 0,44 & 0,44 & 0,44 & 0,44 & 0,44 \\
\hline Metionina $(\%)$ & 0,54 & 0,56 & 0,54 & 0,55 & 0,55 & 0,54 & 0,55 \\
\hline Aminoácidos sulfurados (\%) & 0,87 & 0,87 & 0,87 & 0,87 & 0,87 & 0,87 & 0,87 \\
\hline \multirow[t]{2}{*}{ Lisina $(\%)$} & 1,22 & 1,22 & 1,22 & 1,22 & 1,22 & 1,22 & 1,22 \\
\hline & \multicolumn{7}{|c|}{ Rações experimentais finais } \\
\hline Milho & 65,31 & 66,95 & 66,47 & 66,54 & 66,64 & 64,50 & 66,77 \\
\hline Farelo de soja & 25,57 & 19,74 & 19,94 & 19,87 & 19,88 & 21,20 & 19,85 \\
\hline Óleo de soja & 2,86 & 2,37 & 2,26 & 2,38 & 1,63 & 2,20 & 1,73 \\
\hline $\mathrm{FCOB}^{(2)}$ & - & 6,00 & - & 3,00 & 2,00 & - & 1,50 \\
\hline $\mathrm{FVA}^{(3)}$ & - & - & 4,30 & 2,20 & - & 1,40 & 1,10 \\
\hline Farelo de trigo & - & - & - & - & 5,30 & 5,30 & 3,90 \\
\hline Levedura de cana & - & - & - & - & 2,30 & 2,30 & 1,70 \\
\hline Calcário calcítico & 0,90 & 0,24 & 0,86 & 0,80 & 0,89 & 0,93 & 0,89 \\
\hline Fosfato bicálcico & 1,35 & - & 0,78 & - & 0,56 & 1,08 & 0,60 \\
\hline DL-Metionina & 0,15 & 0,17 & 0,13 & 0,15 & 0,16 & 0,14 & 0,15 \\
\hline L-Lisina & 0,16 & 0,21 & 0,17 & 0,19 & 0,18 & 0,17 & 0,19 \\
\hline Caulim & 3,13 & 3,76 & 4,50 & 4,35 & - & - & 1,06 \\
\hline Sal comum & 0,37 & 0,37 & 0,37 & 0,37 & 0,37 & 0,37 & 0,37 \\
\hline Cloreto de colina $70 \%$ & 0,05 & 0,05 & 0,05 & 0,05 & 0,05 & 0,05 & 0,05 \\
\hline Supl. vitamínico ${ }^{(6)}$ & 0,10 & 0,10 & 0,10 & 0,10 & 0,10 & 0,10 & 0,10 \\
\hline Supl. mineral ${ }^{(5)}$ & 0,05 & 0,05 & 0,05 & 0,05 & 0,05 & 0,05 & 0,05 \\
\hline Total & 100,00 & 100,00 & 100,00 & 100,00 & 100,00 & 100,00 & 100,00 \\
\hline \multicolumn{8}{|c|}{ Composição nutricional calculada } \\
\hline $\mathrm{EM}\left(\mathrm{kcal} \mathrm{kg}^{-1}\right)$ & 3.050 & 3.050 & 3.050 & 3.050 & 3.050 & 3.050 & 3.050 \\
\hline PB $(\%)$ & 17,20 & 17,20 & 17,20 & 17,20 & 17,20 & 17,20 & 17,20 \\
\hline Cálcio $(\%)$ & 0,76 & 0,76 & 0,76 & 0,76 & 0,76 & 0,76 & 0,76 \\
\hline P disponível (\%) & 0,35 & 0,50 & 0,35 & 0,35 & 0,35 & 0,35 & 0,35 \\
\hline Metionina $(\%)$ & 0,43 & 0,44 & 0,42 & 0,43 & 0,43 & 0,42 & 0,43 \\
\hline Aminoácidos sulfurados (\%) & 0,71 & 0,71 & 0,71 & 0,71 & 0,71 & 0,71 & 0,71 \\
\hline Lisina $(\%)$ & 0,99 & 0,99 & 0,99 & 0,99 & 0,99 & 0,99 & 0,99 \\
\hline
\end{tabular}

${ }^{(1)} \mathrm{TC}$, tratamento controle; FC, farinha de carne e ossos bovina; FV, farinha de vísceras de aves; FCV, farinha de carne e ossos bovina e farinha de vísceras de aves; FCLT, farinha de carne e ossos bovina, levedura de cana-de-açúcar e farelo de trigo; FVLT, farinha de vísceras de aves, levedura de cana-de-açúcar e farelo de trigo; FCVLT, farinha de carne e ossos bovina, farinha de vísceras de aves, levedura de cana-de-açúcar e farelo de trigo. ${ }^{(2)}$ Farinha de carne e ossos bovinos. ${ }^{(3)}$ Farinha de vísceras de aves. ${ }^{(4)}$ Suplemento vitamínico (por kg de ração): vitamina A, 9.900 UI; vitamina D, 2.750 UI; vitamina E, 22 mg; ácido nicotínico, 27,5 mg; vitamina $\mathrm{K}, 2,75 \mathrm{mg}$; ácido pantotênico, $13,2 \mathrm{mg}$; ácido fólico, $0,88 \mathrm{mg}$; vitamina $\mathrm{B}_{1}, 1,65 \mathrm{mg}$; vitamina $\mathrm{B}_{2}$, 6,6 mg; vitamina $\mathrm{B}_{6}, 3,3 \mathrm{mg}$; vitamina $\mathrm{B}_{12}, 13,2 \mu \mathrm{g}$; selênio, $0,275 \mathrm{mg}$. ${ }^{(5)}$ Suplemento mineral (por kg de ração): cobre, $10 \mathrm{mg}$; ferro, $50 \mathrm{mg}$; iodo, $1 \mathrm{mg}$; manganês, $80 \mathrm{mg}$; zinco, $50 \mathrm{mg}$; cobalto, $1 \mathrm{mg} .{ }^{(6)}$ Suplemento vitamínico (por kg de ração): vitamina A, 7.200 UI; vitamina D, 2.000 UI; vitamina E, 16 mg; ácido nicotínico, $20 \mathrm{mg}$; vitamina K, $2 \mathrm{mg}$; ácido pantotênico, $9,6 \mathrm{mg}$; ácido fólico, $0,64 \mathrm{mg}$; vitamina. $\mathrm{B}_{1}, 1,2 \mathrm{mg}$; vitamina $\mathrm{B}_{2}, 4,8 \mathrm{mg}$; vitamina $\mathrm{B}_{6}, 2,4 \mathrm{mg}$; vitamina $\mathrm{B}_{12}$, $9,6 \mu \mathrm{g}$; selênio, $0,2 \mathrm{mg}$. 
identificadas, acondicionadas em sacos de plástico e congeladas a $-20^{\circ} \mathrm{C}$, para análises isotópicas posteriores.

Para a realização das análises isotópicas, as amostras foram descongeladas e secadas em estufa de ventilação forçada, a $56^{\circ} \mathrm{C}$ por 48 horas. Em seguida, cada amostra foi moída em moinho criogênico de nitrogênio líquido, a $-196^{\circ} \mathrm{C}$ por $3 \mathrm{~min}$ (tecido) e $5 \mathrm{~min}$ (rações), em freqüência máxima, para a obtenção de um material homogêneo e de finíssima granulometria (partículas $<60 \mu \mathrm{m}$ ), com aspecto microscópico (Rosa et al., 2002). As análises foram realizadas na Unesp, Campus de Botucatu, Centro de Isótopos Estáveis do Instituto de Biociências.

As amostras moídas foram pesadas em cápsulas de estanho, e tiveram as seguintes massas: peito, 50 a $60 \mu \mathrm{g}$ e 500 a $600 \mu \mathrm{g}$, e os ingredientes e a ração, 60 a $70 \mu \mathrm{g}$ e 1.600 a $1.700 \mu \mathrm{g}$, para a determinação das razões isotópicas do carbono e nitrogênio, respectivamente. As cápsulas foram introduzidas, por meio de amostrador automático, no analisador elementar, em que, em presença de oxigênio $\left(\mathrm{O}_{2}\right)$ e óxido de cobre $(\mathrm{CuO})$, a amostra foi queimada, para a obtenção de $\mathrm{CO}_{2}$ e $\mathrm{NO}_{x}$; este último foi, então, reduzido a $\mathrm{N}_{2}$ em presença de cobre. Os gases formados foram separados em coluna cromatográfica gasosa e analisados no espectrômetro de massas de razões isotópicas.

Os resultados das análises isotópicas foram expressados em delta $(\delta)$ por mil, relativos aos padrões internacionais Peedee Belemnite (PDB) para o ${ }^{13} \mathrm{C}$ e ao nitrogênio atmosférico para ${ }^{15} \mathrm{~N}$, de acordo com a seguinte equação geral: $\delta \mathrm{X}_{\text {(amostra, padrão) }}=1000\left[\left(\mathrm{R}_{\text {amostra }}\right.\right.$ $\mathrm{R}_{\text {padrão }} / \mathrm{R}_{\text {padrão }}$, em que: $\delta \mathrm{X}$ representa o enriquecimento do isótopo menos abundante do elemento químico $\mathrm{X}\left({ }^{13} \mathrm{C}\right.$ ou $\left.{ }^{15} \mathrm{~N}\right)$ da amostra, em relação ao respectivo padrão internacional, e $\mathrm{R}$ representa a razão isotópica entre o menos e o mais abundante isótopo, em particular ${ }^{13} \mathrm{C} /{ }^{12} \mathrm{C}$ e ${ }^{15} \mathrm{~N} /{ }^{14} \mathrm{~N}$.

Os resultados isotópicos obtidos foram submetidos à análise multivariada de variância (MANOVA), com auxílio do procedimento GLM do SAS (SAS Institute, 1996). A partir dos dados gerados pelas matrizes de erro, foram determinadas regiões com $95 \%$ de confiança para a comparação entre os tratamentos experimentais.

\section{Resultados e Discussão}

Os resultados obtidos com as análises isotópicas do músculo peitoral dos frangos de corte, alimentados com os tratamentos experimentais, mostraram enriquecimento tanto em carbono quanto em nitrogênio (Tabela 2), em comparação ao tratamento controle, e o mesmo comportamento foi observado quanto às dietas (Tabela 3).

A base de todas as dietas experimentais foi a mesma, ou seja, milho e farelo de soja; assim, esse enriquecimento ocorreu pela diferença na composição das dietas dos tratamentos aplicados (Tabela 4).

O enriquecimento das dietas em carbono-13 ocorreu, provavelmente, em conseqüência do enriquecimento isotópico das plantas $\mathrm{C}_{4}$ em comparação às $\mathrm{C}_{3}$ (Vogel, 1993), além de o valor isotópico da farinha de origem animal ser reflexo do sinal isotópico da dieta do animal que a originou, em torno de $2 \%$ para o $\delta^{13} \mathrm{C}$ (DeNiro \& Epstein, 1978). Em nitrogênio-15, o enriquecimento ocorreu em razão da diminuição da inclusão do farelo de soja de valor isotópico próximo ao padrão (Handley \& Raven, 1992; Werner \& Schimidt, 2002), associada ao aumento do milho (Choi et al., 2002) e da farinha de origem animal, ricos isotopicamente em nitrogênio-15.

A inclusão de farinha de carne e ossos bovina, farinha de vísceras de aves e levedura enriqueceram as dietas, tanto em carbono-13 como em nitrogênio-15. $\mathrm{O}$ farelo de trigo contribuiu apenas no enriquecimento em nitrogênio-15, pois ele é mais pobre em carbono-13 do que os demais ingredientes. Enriquecimento em carbono-13 e nitrogênio-15, quando utilizadas farinhas de origem animal em dieta de frangos de corte, também foram observados por Oliveira (2005) e Carrijo et al. (2006).

Tabela 2. Valores médios de $\delta^{13} \mathrm{C}$ e $\delta^{15} \mathrm{~N}$, com os respectivos desvios-padrão, do músculo peitoral $(\mathrm{n}=4)$ de frangos de corte.

\begin{tabular}{lcc}
\hline Tratamento $^{(1)}$ & \multicolumn{2}{c}{ Músculo peitoral } \\
\cline { 2 - 3 } & $\delta^{13} \mathrm{C}(\% \circ)^{(2)}$ & $\delta^{15} \mathrm{~N}(\% \circ)^{(2)}$ \\
\hline TC & $-18,24 \pm 0,12$ & $2,06 \pm 0,13$ \\
FC & $-17,41 \pm 0,15$ & $2,94 \pm 0,16$ \\
FV & $-17,03 \pm 0,14$ & $2,85 \pm 0,09$ \\
FCV & $-16,98 \pm 0,10$ & $2,77 \pm 0,09$ \\
FCLT & $-17,73 \pm 0,12$ & $3,02 \pm 0,16$ \\
FVLT & $-17,56 \pm 0,09$ & $2,55 \pm 0,08$ \\
FCVLT & $-16,96 \pm 0,20$ & $3,01 \pm 0,11$ \\
\hline
\end{tabular}

${ }^{(1)} \mathrm{TC}$, tratamento controle; FC, farinha de carne e ossos bovina; FV, farinha de vísceras de aves; FCV, farinha de carne e ossos bovina e farinha de vísceras de aves; FCLT, farinha de carne e ossos bovina, levedura de canade-açúcar e farelo de trigo; FVLT, farinha de vísceras de aves, levedura de cana-de-açúcar e farelo de trigo; FCVLT, farinha de carne e ossos bovina, farinha de vísceras de aves, levedura de cana-de-açúcar e farelo de trigo. ${ }^{(2)}$ Valores isotópicos, calculados em relação ao padrão internacional PDB para o carbono e em relação ao $\mathrm{N}$ atmosférico para o nitrogênio. 
Tabela 3. Valores médios de $\delta^{13} \mathrm{C}$ e $\delta^{15} \mathrm{~N}$, com seus desvios-padrão $(\mathrm{n}=2)$, da ração de frangos de corte criados até os 42 dias de idade.

\begin{tabular}{lccccc}
\hline Tratamento $^{(1)}$ & \multicolumn{2}{c}{ Ração inicial } & & \multicolumn{2}{c}{ Ração final } \\
\cline { 2 - 3 } & $\delta^{13} \mathrm{C}(\% 0)^{(2)}$ & $\delta^{15} \mathrm{~N}(\%)^{(2)}$ & & $\delta^{13} \mathrm{C}(\%)^{(2)}$ & $1,79 \pm 0,10$ \\
TC & $-17,35 \pm 0,09$ & $1,57 \pm 0,08$ & & $-17,01 \pm 0,07$ & $2,38 \pm 0,08$ \\
FC & $-16,24 \pm 0,11$ & $2,14 \pm 0,20$ & & $-16,38 \pm 0,14$ & $2,60 \pm 0,11$ \\
FV & $-16,58 \pm 0,14$ & $2,47 \pm 0,07$ & & $-16,02 \pm 0,08$ & $2,35 \pm 0,15$ \\
FCV & $-16,03 \pm 0,12$ & $2,03 \pm 0,12$ & & $-16,19 \pm 0,05$ & $2,62 \pm 0,06$ \\
FCLT & $-18,10 \pm 0,06$ & $2,10 \pm 0,08$ & & $-17,04 \pm 0,12$ & $2,37 \pm 0,11$ \\
FVLT & $-17,28 \pm 0,14$ & $1,90 \pm 0,07$ & & $-16,65 \pm 0,06$ & $2,71 \pm 0,13$ \\
FCVLT & $-17,10 \pm 0,07$ & $1,92 \pm 0,04$ & & $-16,05 \pm 0,09$ & \\
\hline
\end{tabular}

${ }^{(1)} \mathrm{TC}$, tratamento controle; FC, farinha de carne e ossos bovina; FV, farinha de vísceras de aves; FCV, farinha de carne e ossos bovina e farinha de vísceras de aves; FCLT, farinha de carne e ossos bovina, levedura de cana-de-açúcar e farelo de trigo; FVLT, farinha de vísceras de aves, levedura de cana-de-açúcar e farelo de trigo; FCVLT, farinha de carne e ossos bovina, farinha de vísceras de aves, levedura de cana-de-açúcar e farelo de trigo. ${ }^{(2)}$ Valores isotópicos, calculados em relação ao padrão internacional PDB para o carbono e em relação ao N atmosférico para o nitrogênio.

Tabela 4. Valores médios de $\delta^{13} \mathrm{C}$ e $\delta^{15} \mathrm{~N}$, com os respectivos desvios-padrão $(n=2)$, dos ingredientes utilizados nas dietas experimentais.

\begin{tabular}{lll}
\hline Ingrediente & $\delta^{13} \mathrm{C}(\%)^{(1)}$ & $\left.\delta^{15} \mathrm{~N}(\%)\right)^{(1)}$ \\
\hline Farinha de carne e ossos bovina & $-12,82 \pm 0,13$ & $7,72 \pm 0,22$ \\
Farinha de vísceras & $-16,28 \pm 0,07$ & $4,29 \pm 0,03$ \\
Levedura & $-10,49 \pm 0,08$ & $4,36 \pm 0,02$ \\
Farelo de trigo & $-26,65 \pm 0,17$ & $4,47 \pm 0,12$ \\
Milho & $-12,60 \pm 0,03$ & $3,57 \pm 0,23$ \\
Farelo de soja & $-27,57 \pm 0,35$ & $0,43 \pm 0,05$ \\
Óleo de soja & $-31,54 \pm 0,21$ & \\
\hline
\end{tabular}

${ }^{(1)}$ Valores isotópicos, calculados em relação ao padrão internacional PDB para o carbono e em relação ao $\mathrm{N}$ atmosférico para o nitrogênio.

Dos ingredientes utilizados, os mais ricos foram o milho, em carbono-13, e a farinha de carne e ossos bovina, em nitrogênio-15, e o mais pobre, em ambos os isótopos, foi o farelo de soja. O comportamento dessas variações nas dietas pôde ser observado no músculo peitoral, visto que sua assinatura isotópica é refletida no organismo dos animais (DeNiro \& Epstein, 1978).

A comparação entre os tratamentos experimentais (inclusão de farinhas de origem animal) e o tratamento controle (dieta vegetal), com a finalidade de identificar a presença de farinhas de origem animal na alimentação das aves, foi feita por meio da análise das regiões de confiança, obtidas pela análise estatística dos valores isotópicos das amostras de músculo (Figura 1).

Foi possível diferenciar entre o controle e os outros tratamentos - mesmo quando houve a adição de levedura e farelo de trigo -, pois a diferença entre as médias dos valores isotópicos de $\delta^{13} \mathrm{C}$ e as médias dos valores isotópicos de $\delta^{15} \mathrm{~N}$ dos tratamentos comparados foi diferente de zero e, assim, a região de confiança não se sobrepôs a nenhum dos eixos do gráfico $(\mathrm{p}<0,05)$.

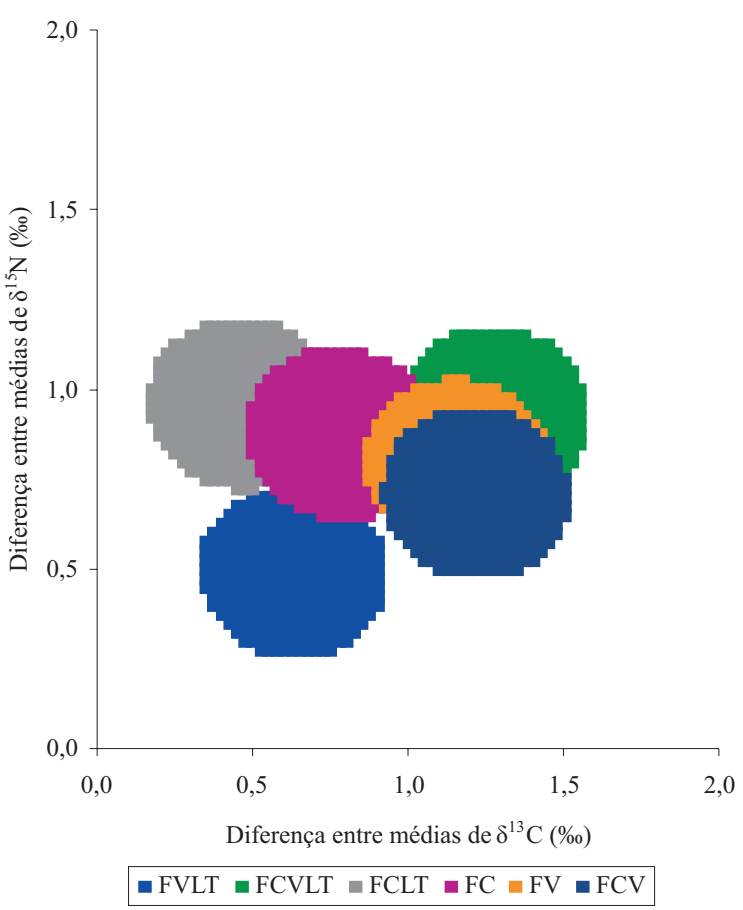

Figura 1. Regiões de confiança, formadas pela diferença entre os valores isotópicos de $\delta^{13} \mathrm{C}$ e $\delta^{15} \mathrm{~N}$, para músculo peitoral de frangos de corte aos 42 dias de idade, de cada tratamento, comparado ao tratamento controle. FVLT, farinha de vísceras de aves, levedura de cana-de-açúcar e farelo de trigo; FCVLT, farinha de carne e ossos bovina, farinha de vísceras de aves, levedura de cana-de-açúcar e farelo de trigo; FCLT, farinha de carne e ossos bovina, levedura de cana-de-açúcar e farelo de trigo; FC, farinha de carne e ossos bovina; FV, farinha de vísceras de aves; FCV, farinha de carne e ossos bovina e farinha de vísceras de aves.

Os dados obtidos estão de acordo com os encontrados por Oliveira (2005) e Carrijo et al. (2006) que, ao estudar frangos de corte, também identificaram a presença de farinhas de origem animal na alimentação das aves, 
pela técnica dos isótopos estáveis. Com sucesso, a técnica também foi aplicada, com o mesmo intuito, em estudos com poedeiras comerciais (Denadai, 2008) e codornas de corte (Móri et al., 2007, 2008).

Portanto, a técnica dos isótopos estáveis de carbono e nitrogênio, no processo de certificação, éuma ferramenta que pode ser utilizada com sucesso, na determinação de ingredientes de origem animal no produto final. Esta técnica também possibilitou a certificação de origem geográfica e regime de alimentação, conforme Piasentier et al. (2003), em estudos com ovinos, e para caracterização do regime dietético de suínos, por meio de análises isotópicas conjuntas de carbono $\left(\delta^{13} \mathrm{C}\right)$ e enxofre $\left(\delta^{34} \mathrm{~S}\right)$ (Gonzáles Martin et al., 2001).

\section{Conclusões}

1. É possível determinar, pela técnica dos isótopos estáveis do carbono e do nitrogênio, a presença de farinhas de origem animal, na alimentação de aves, por meio da análise do músculo peitoral.

2. Ainclusão de levedura e farelo de trigo, na dieta das aves, não impede a detecção, pela técnica de isótopos estáveis do carbono e do nitrogênio, da presença de farinhas de origem animal na ração das aves.

\section{Referências}

BELLAVER, C.; COSTA, C.A.F.; FRAHA, V.S.A.; LIMA, G.J.M.M.; HACKERNHAR, L.; BALDI, P. Substituição de farinhas de origem animal por ingredientes de origem vegetal em dietas para frangos de corte. Ciência Rural, v.35, p.671-677, 2005.

BRICOUT, J.; KOZIET, J. Control of the authenticity of orange juice by isotopic analysis. Journal of Agricultural Food Chemistry, v.35, p.758-760, 1987.

BROOKES, S.T.; BARRIE, A.; DAVIES, J.E. A rapid ${ }^{13} \mathrm{C} /{ }^{12} \mathrm{C}$ test for determination of corn-syrups in honey. Journal of the Association of Official Analytical Chemists, v.74, p.627-629, 1991.

CARRIJO, A.S.; PEZZATO, A.C.; DUCATTI, C.; SARTORI, J.R.; TRINCA, L.; SILVA, E.T. Traceability of bovine meat and bone meal in poultry by stable isotope analysis. Revista Brasileira de Ciência Avícola, v.8, p.37-42, 2006.

CHOI, W.J.; LEE, S.M.; RO, H.M.; KIM, K.C.; YOO, S.H. Natural ${ }^{15} \mathrm{~N}$ abundances of maize and soil amended with urea and composted pig manure. Plant and Soil, v.245, p.223-232, 2002.

COMUNIDADE EUROPÉIA. Regulamento (CE) nํㅜ 1760/2000. Official Journal of the European Communities, 2000. Disponível em: <http://europa.eu.int/smartapi/cgi/sga_doc?smartapi!celexapi! prod!CELEXnumdoc $\&$ lg=PT\&numdoc $=32000 \mathrm{R} 1760 \&$ model $=\mathrm{gu}$ ichett>. Acesso em: 20 jan. 2007.
COMUNIDADE EUROPÉIA. Regulamento (CE) nº 1774/2002. Official Journal of the European Communities, 2002. Disponível em: <http://europa.eu.int/smartapi/cgi/sga_doc?smartapi!celexapi! prod!CELEXnumdoc \&lg=PT\&numdoc $=32002 \mathrm{R} 1774 \&$ model $=$ gu ichett>. Acesso em: 20 out. 2004.

DENADAI, J.C. Rastreabilidade de farinhas de origem animal em ovos de poedeiras comercias pela técnica dos isótopos estáveis do carbono $\left(\delta^{13} \mathbf{C}\right)$ e do nitrogênio $\left(\delta^{15} \mathbf{N}\right)$. 2008. 90 p. Tese (Doutorado) - Universidade Estadual Paulista, Botucatu.

DeNIRO, M.J.; EPSTEIN, S. Influence of diet on the distribution of carbon isotopes in animals. Geochimica et Cosmochimica Acta, v.42, p.495-506, 1978.

GONZÁLEZ MARTIN, I.; GONZÁLEZ PÉREZ, C.; HERNÁNDEZ MÉNDEZ, J.; SÁNCHEZ GONZÁLEZ, C. Differentiation of dietary regimen of Iberian swine by means of isotopic analysis of carbon and sulphur in hepatic tissue. Meat Science, v.58, p.25-30, 2001

GONZÁLEZ MARTIN, I.; GONZÁLEZ PÉREZ, C.; HERNÁNDEZ MÉNDEZ, J.; SÁNCHEZ GONZÁLEZ, C. Use of isotope analysis to characterize meat from Iberian-breed swine. Meat Science, v.52, p.437-441, 1999.

HANDLEY, L.L.; RAVEN, J.A. The use of natural abundance of nitrogen isotopes in plant physiology and ecology. Plant Cell and Environment, v.15, p.965-985, 1992.

IBA, S.K.; BRABET, C.; OLIVEIRA, I.J.O.; PALlET, D. Um panorama da rastreabilidade dos produtos agropecuários do Brasil destinados à exportação - carnes, soja e frutas. Disponível em: <http://www.cendotec1.org.br/dossier/cirad/ produitsbrpr.pdf $>$. Acesso em: 15 mar. 2003.

ILBERY, B.; KNEAFSEY, M.; BAMFORD, M. Protecting and promoting regional speciality food and drink products in the European Union. Outlook on Agriculture, v.29, p.31-37, 2000.

KELLY, S.; PARKER, I.; SHARMAN, M.; DENNIS, J.; GOODALL, I. Assessing the authenticity of single-seed vegetable oils using fatty acid stable carbon isotope ratios $\left({ }^{13} \mathrm{C} /{ }^{12} \mathrm{C}\right)$. Food Chemistry, v.59, p.181-186, 1997.

KOZIET, J.; ROSSMANN, A.; MARTIN, G.J.; ASHURST, P.R. Determination of carbon-13 content of sugars of fruit and vegetable juices. Analytica Chimica Acta, v.271, p.31-38, 1993.

MANCA, G.; CAMIN, F.; COLORU, G.; Del CARO, A.; DETENTORI, D.; FRANCO, M.A.; VERSINI, G. Characterization of the geographical origin of Pecorino Sardo cheese by casein stable isotope $\left({ }^{13} \mathrm{C} /{ }^{12} \mathrm{C}\right.$ and $\left.{ }^{15} \mathrm{~N} /{ }^{14} \mathrm{~N}\right)$ ratios and free-amino acid ratios. Journal of Agricultural and Food Chemistry, v.49, p.1404-1409, 2001.

MARTIN, G.J.; GUILLOU, C.; MARTIN, M.L.; CABANIS, M.T.; TEP, X.; AERNY, J. Natural factors of isotope fractionation and the characterization of wines. Journal of Agricultural and Food Chemistry, v.36, p.316-322, 1988.

MÓRI, C.; GARCIA, E.A.; DUCATTI, C.; DENADAI, J.C.; GOTTMANN, R.; MITUO, M.A.O. Poultry offal meal traceability in meat quail tissues using the technique of stable carbon $\left({ }^{13} \mathrm{C} /{ }^{12} \mathrm{C}\right)$ and nitrogen $\left({ }^{15} \mathrm{~N} /{ }^{14} \mathrm{~N}\right)$ isotopes. Revista Brasileira de Ciência Avícola, v.10, p.45-52, 2008. 
MÓRI, C.; GARCIA, E.A.; DUCATTI, C.; DENADAI, J.C.; PELÍCIA, K.; GOTTMANN, R.; MITUO, M.A.O.; BORDINHON, A.M. Traceability of animal byproducts in quail (Coturnix coturnix japonica) tissues using carbon $\left({ }^{13} \mathrm{C} /{ }^{12} \mathrm{C}\right)$ and nitrogen $\left({ }^{15} \mathrm{~N} /{ }^{14} \mathrm{~N}\right)$ stable isotopes. Revista Brasileira de Ciência Avícola, v.9, p.263-269, 2007.

OLIVEIRA, R.P. Rastreabilidade da farinha de vísceras de aves na alimentação de frangos de corte pela técnica dos isótopos estáveis $\left(\delta^{13} \mathbf{C} \mathbf{e} \delta^{15} \mathbf{N}\right) \cdot 2005$. 109p. Tese. (Doutorado) - Universidade Estadual Paulista, Botucatu.

PIASENTIER, E.; VALUSSO, R.; CAMIN, F.; VERSINI, G. Stable isotope ratio analysis for authentication of lamb meat. Meat Science, v.64, p.239-247, 2003.

REGATTIERI, A.; GAMBERI, M.; MANZINI, R. Traceability of food products: General framework and experimental evidence. Journal of Food Engineering, v.81, p.347-356, 2007.

ROSA, C.R.; MORAES, M.; GOMES NETO, J.A.; NÓBREGA, J.A.; NOGUEIRA, A.R. Effect of modifiers on thermal behavior of Se in acid digestates and slurry of vegetables by graphite furnace atomic absorption spectrometry. Food Chemistry, v.79, p.517-523, 2002.

ROSTAGNO, H.S.; ALBINO, L.F.T.; DONZELE, J.L.; GOMES, P.C.; OLIVEIRA, R.F.; LOPES, D.C.; FERREIRA,
A.S.; BARRETO, S.L.T. Composição de alimentos e exigências nutricionais. Tabelas brasileiras para aves e suínos. 2.ed. Viçosa: Editora UFV, 2005. 186p.

ROSSMANN, A.; HABERHAUER, G.; HOLZL, S.; HORN, P.; PICHLMAYER, F.; VOERKELIUS, S. The potential of multielement stable isotope analysis for regional origin assignment of butter. European Food Research \& Technology, v.211, p.32-40, 2000.

SAS INSTITUTE. SAS/STAT user's guide. Version 6.11. 4.ed. v.2. Cary: SAS Institute, 1996. 842p.

VOGEL, J.C. Variability of carbon isotope fractionation during photosynthesis. In: EHLERINGER, J.R.; HALL, A.E.; FAQUHAR, G.D. (Ed.). Stable isotopes and plant carbon-water relations. San Diego: Academic Press, 1993. p.29-46.

WERNER, R.A.; SCHIMIDT, H.L. The in vivo nitrogen isotope discrimination among organic plant compounds. Phytochemistry, v.61, p.465-484, 2002

WHITE, J.W.; WINTERS, K.; MARTIN, P.; ROSSMANN, A. Stable carbon isotope ratio analysis of honey: validation of internal standard procedure for worldwide application. Journal of the Association of Official Analytical Chemists International, v.81, p.610-619, 1998.

Recebido em 26 de setembro de 2008 e aprovado em 10 de novembro de 2008 